\title{
Sociobiology
}

RESEARCH ARTICLE - ANTS

\section{Myrmecophily and Myrmecophagy of Attacobius lavape (Araneae: Corinnidae) on Solenopsis saevissima (Hymenoptera: Myrmicinae)}

\author{
CAF MENDONÇA ${ }^{1}$, MA PESQUERO $^{1}$, RSD CARVALHO $^{2}$, FV ARRUdA $^{3}$
}

1 - Programa de Pós-Graduação em Ambiente e Sociedade, Universidade Estadual de Goiás, Morrinhos, Brazil

2 - Curso de Graduação em Ciências Biológicas, Universidade Estadual de Goiás, Morrinhos, Brazil

3 - Programa de Pós-Graduação em Recursos Naturais do Cerrado, Universidade Estadual de Goiás, Anápolis, Brazil

\begin{tabular}{|c|c|}
\hline Article History & \\
\hline Edited by & \\
\hline Kleber Del-Claro, $\iota$ & JFU, Brazil \\
\hline Received & 20 March 2019 \\
\hline Initial acceptance & 25 July 2019 \\
\hline Final acceptance & 02 October 2019 \\
\hline Publication date & 30 December 2019 \\
\hline Keywords & \\
\hline $\begin{array}{l}\text { Fire ant, inquiline, } \\
\text { biological control. }\end{array}$ & social parasite, \\
\hline Corresponding au & thor \\
\hline Marcos Antônio Pe & esquero \\
\hline Programa de Pós- & Graduação em \\
\hline Ambiente e Socied & dade \\
\hline Universidade Esta & dual de Goiás \\
\hline Rua Rio de Janeiro & no 99, Centro \\
\hline CEP 75650-000. M & lorrinhos-GO, Brasil. \\
\hline E-Mail: mapesq@u & ueg.br \\
\hline
\end{tabular}

Article History

Edited by

Kleber Del-Claro, UFU, Brazil

Initial acceptance 25 July 2019

Final acceptance 02 October 2019

\section{Keywords}

Fire ant, inquiline, social parasite,

\section{Corresponding author}

Marcos Antonio Pesquero

Programa de Pós-Graduação em

Rua Rio de Janeiro no 99, Centro

E-Mail: mapesq@ueg.br

\begin{abstract}
Attacobius lavape, a small spider from the Corinnidae family, has been recently described living inside a fire ant colony of Solenopsis saevissima species in the municipality of Morrinhos, south region of the Goiás State, Brazil. Yet several aspects of this spider relationship with the host ant remain unknown. In this way, we performed an extension study to determine its local (Morrinhos) and regional (latitudinal transect) occurrence. We also investigated if the spider uses the host ant as a feeding source. For this, we established arenas with a known number of young and adult ant individuals plus one spider and observed the feeding rate for some determined time. Regarding local distribution, differently from most socially parasitic myrmecophiles, A. lavapes howed high local infestation, being found in $47 \%$ of the colonies in the sites where the spider occurred, and high transmission, being found in $42 \%$ of the 12 collection sites. Regionally, among the 11 study sites, this species only occurred in the municipality of Morrinhos, but its distribution still needs to be verified in the north region. Attacobius lavape consumed eggs, larvae and pupae, confirming that the myrmecophily was explained by myrmecophagy. The spiders consumed eggs (not estimated), $4.45 \pm 2.14$ larvae and/or $3 \pm 0.87$ pupae per day. Considering that the mean abundance was approximately seven spiders per colony (extent 1-23), we foresee an impact of 35 larvae and/or 21 pupae consumed per day in each hosting colony. The possibility of consuming sexualeggs, larvae and pupae classifies A. lavape as a potential agent of biological control of S. saevissima.
\end{abstract}

\section{Introduction}

Ants are social insects divided into castes from which workers are known for their capability to defend the colony against natural enemies (Hölldobler \& Wilson, 1990). This altruistic behavior is justified by the high degree of relatedness among colony members (Hamilton, 1964). Thus, any strange organism that gets closer to the colony is considered a threat to be fought. However, many arthropod species (mainly insects) that live close to or inside the ant colonies, known as myrmecophiles, have to surpass this biological barrier (Hölldobler \& Wilson, 1990). Despite the risks of living with a group of so aggressive animals, the benefits a colony can offer, such as food and protection against predators, should overcome the costs, otherwise the selection would not have favored this behavior (Ceccarelli, 2013).

Myrmecophily occurs in only 41 spider species ( $\sim .1 \%$ of all described species), belonging to 12 of the 112 described families (Cushing, 1997, 2012). However, most of the studies focus on myrmecomorphy and myrmecophagy in spiders and little knowledge has been produced so far about myrmecophily, mainly the social integration and the spider impact to the colony fitness (Cushing, 1997, 2012). While some species seem to be opportunistic hosts, others establish obligatory relationships, using several morphological, behavioral and chemical strategies for the integration into the host colony life (Cushing, 1997, 2012). 
The genus Attacobius Mello-Leitão, 1925 (Corinnidae) is composed of 16 known species (WSC, 2019), occurring from the central region of Argentina up to the Brazilian northeast region (Bonaldo, 2000). Myrmecophily is confirmed in three species of genus Attacobius (Attacobius luederwaldti (Mello-Leitão, 1923), Attacobius attarum (Roewer, 1935), and Attacobius lavape Bonaldo, Pesquero and Brescovit, 2018 (Platnick \& Batista, 1995; Erthal \& Tonhasca, 2001; Ichinose et al., 2004; Bonaldo et al., 2018; Pereira-Filho et al., 2018). However, the interaction incidences inside this group can be higher than registered so far, because other species of Attacobius were collected through pitfall traps, yet without information on association with ants (Bonaldo \& Brescovit, 2005).

In the municipality of Morrinhos, south region of the Goiás State, we have found adults (males and females) and young A. lavape inside the Solenopsis saevissima (F. Smith, 1855) colonies. Solenopsis saevissima has a wide distribution in South America and, as well as other 19 species belonging to the fire ants, it is known by its painful sting and mass attack (Pitts et al., 2018). Similar to the Solenopsis invicta Buren, 1972 species in the south region of the United States, when introduced in other regions, the fire ants can cause serious structural, ecological and public health problems (Tschinkel, 2006). Several fly species of the genus Pseudacteon (Diptera: Phoridae) and Orasema xanthopus (Cameron, 1909) (Hymenoptera: Eucharitidae) are known parasitoids of $S$. saevissima (Pesquero \& Dias, 2004, 2011), and the discovery of this new spider species expands the number of natural enemies with potential use in biological control programs.

The mechanisms and adaptations involved in myrmecophily of $A$. lavape on $S$. saevissima, as well as the impact they cause on the hosting colony have not yet been described since the recent discovery of the spider $A$. lavape (Bonaldo et al., 2018). Therefore, we aim to describe the behaviors that allow myrmecophily and to verify the impact caused on the hosting colony. We seek to find if:i) The occurrence of $A$. lavape fits one of the three models of the distribution of social parasites (high infestation and low transmission, low infestation and high(ish) transmission, low infestation and very low transmission) proposed by Thomas et al. (2005). ii) Myrmecophily is a strategy for using the ant host as a food source (Erthal \& Tonhasca, 2001). iii) Attacobius lavape has plasticity in the use of host ant species as already documented for some spider species (Cushing, 1997, 2012).

\section{Material and Methods}

\section{Local and regional distribution}

We performed the local collections during the transition from the rainy to the dry season (February to April) from 2016 to 2017, in 12 sites in the municipality of Morrinhos, Goiás,

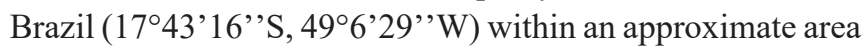
of 59,673 ha. The distance between each point and its nearest neighbor was $6.99 \pm 2.63 \mathrm{Km}$. We have also performed 11 regional collections every $50 \mathrm{~km}$, from Morrinhos to São

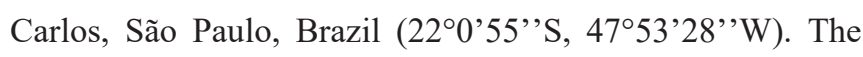
study sites were chosen according to adequate characteristics for the occurrence of $S$. invicta, that is, humid soil with a predominance of low vegetation (pasture) and close to streams (LeBrun et al., 2012). The predominant native vegetation in the study region is the Cerrado lato sensu. The $S$. saevissima colonies found in the study sites were gradually transferred with a shovel to white plastic trays $(50 \times 30 \times 7 \mathrm{~cm})$ to verify the presence of A. lavape. We quantified the collecting areas (ha), the number of colonies found and the number of $A$. lavape individuals present in the colonies to estimate the local and regional occurrence of ants and spiders. We followed Pitts et al. (2018) review for the identification of fire ants and Bonaldo et al. (2018) for the identification of the inquiline spider.

\section{Myrmecophagy}

We used 10 males and 10 females of $A$. lavape in the laboratory for predation tests $(\mathrm{n}=20)$. The predation of $A$. lavape over $S$. saevissima was evaluated through a very small colony offer (10 larvae, 10 pupae, 40 adult workers, 2 males and 2 virgin queens) for an adult spider (male or female) per Petri dish (10x1 $\mathrm{cm}$ ) with lids on during 24 hours. The larvae and pupae offered to the spiders measured in average $1.82 \pm 0.7 \mathrm{~mm}(\mathrm{n}=200)$ and $2.75 \pm 0.45 \mathrm{~mm}$ of length $(\mathrm{n}=200)$, respectively. The adult workers measured in average $4.15 \pm 1.41 \mathrm{~mm}$ of total length. Due to the difficulty of counting and sensibility to manipulation, the eggs were offered to the spiders together with 1 fertile queen and 10 workers. In this way, analyses of predation on eggs was quantified in the event occurrence rate (each time the spiders caught an eggs mass to eat) during one hour of observation for each spider $(n=20)$. Larvae and pupae predation rates were compared by the U test of Mann-Whitney (Ayres et al., 2007).

\section{Hosting Plasticity}

In order to verify the specificity of A. lavape myrmecophily at $S$. saevissima colony-level, we separately inserted 11 adult spiders (7 female and 4 male) in two plastic trays (30x15x10 cm) internally coated with fluon ${ }^{\circledR}$ containing other two $S$. saevissima colonies different from the spider original colony. We observed the spider behavior for 30 minutes or until it was accepted by the colony (we consider that there was acceptance when the spider joined the group of workers without being attacked), totaling 198 minutes of observation ad libitum sense (Del-Claro, 2010). Since it was necessary to verify the specificity of $A$. lavape myrmecophily at the level of the fire ant species, we used the same previous procedures and $11 \mathrm{~A}$. lavape individuals, but with two S. invicta colonies collected in the municipality of São Carlos, São Paulo State, totaling 203 minutes of observation. The acceptance frequency of $A$. lavape inside and among the fire ant species were compared by chi-square tests $\left(\chi^{2}\right)$ for proportions equally expected and Fischer exact probability, respectively, and the time it took the spiders to be accepted by the two fire ant species were compared by the U test of MannWhitney (Ayres et al., 2007). The mean values presented in the text are accompanied by their standard deviations. 


\section{Results}

\section{Local and regional distribution}

We inspected a total of $103 \mathrm{~S}$. saevissima colonies in Morrinhos $(\mathrm{GO})$ and the average density found in the 12 study sites was $12.95 \pm 6.48$ colonies/ha $(2,4,5,5,6,7,7,7,8,13,15$, 24 colonies). From the 108 spiders collected inside the colonies, 17 were males, 54 females, 31 young and 6 that escaped were not sexed. Attacobius lavape occurred in five (42\%) of the 12 sites visited, in $47.4 \pm 25.7 \%$ of the colonies in the sites where it occurred, and in $24.3 \%$ of the 103 colonies found. In average, we found $6.75 \pm 6.94$ spiders/colony ( 1 to 23 individuals, $n=25$ ). Between Morrinhos (GO) and São Carlos (SP), we opened 47 colonies of $S$. saevissima, but no spider was found.

\section{Myrmecophagy}

We found no predation on adult workers, male, and virgin queen of $S$. saevissima offered to spiders during 24 hours. On the other hand, the spiders predated larvae and pupae using more larvae than pupae as food $(4.45 \pm 2.14$ larvae/day vs. $3 \pm$ 0.87 pupae/day, Mann-Whitney, $\mathrm{U}=20, \mathrm{p}=0.004, \mathrm{n}=20$ ). In 12 of the 20 repetitions of one-hour observations, the spiders collected eggs clutch from the workers and immediately started to ingest its content (see Supplementary Material online).

\section{Hosting Plasticity}

From the 11 adult spiders that were introduced in each of the two trays containing $S$. saevissima colonies $(\mathrm{n}=22), 13$ were accepted within $30 \mathrm{~min}$ of observation and 9 were not accepted $\left(\chi^{2}=0.73, p=0.39\right)$. From the 11 spiders introduced in each of the two $S$. invicta colonies, 15 were accepted and 7 were not accepted $\left(\chi^{2}=2.9, \mathrm{p}=0.09\right)$. The frequency of spiders that were accepted by the $S$. saevissima and $S$. invicta colonies did not differ between themselves (59\% vs. 68\%, respectively. Fischer's exact test, $\mathrm{p}=0.34$ ). The average spent time for the spiders to be accepted by the colonies was $9 \pm 6 \mathrm{~min}(\mathrm{n}=28)$ and did not differ between the species of fire ants (Mann-Whitney $\mathrm{U}=53, \mathrm{p}=0.71, \mathrm{n}=28$ ). Inside the trays containing fire ant colonies, the spiders exhibited the behaviors of persecution, touching, avoidance, auto-grooming and stationary (Table 1, Figs 1, 2). After being accepted inside the colonies, the spiders used all the appendages during the contact with the ants, but mainly the first pairs of legs and the pedipalps, which were constantly taken to the chelicerae for auto-grooming.

Table 1. Frequency of behaviors exhibited by Attacobius lavape inside fire ant colonies Solenopsis saevissima and Solenopsis invicta in laboratory.

\section{Behavior}

Frequency (\%)

\begin{tabular}{lc}
\hline Persecution & 26.94 \\
$\quad$ Closely following the workers & \\
Touching & 26.68 \\
$\quad$ Contacting the workers through all the appendices & \\
Avoidance & 19.95 \\
$\quad$ Escaping and dodging the workers & 15.71 \\
Auto-grooming & \\
$\quad$ Passing the first pair of legs on the chelicerae & 10.72 \\
Stationary &
\end{tabular}

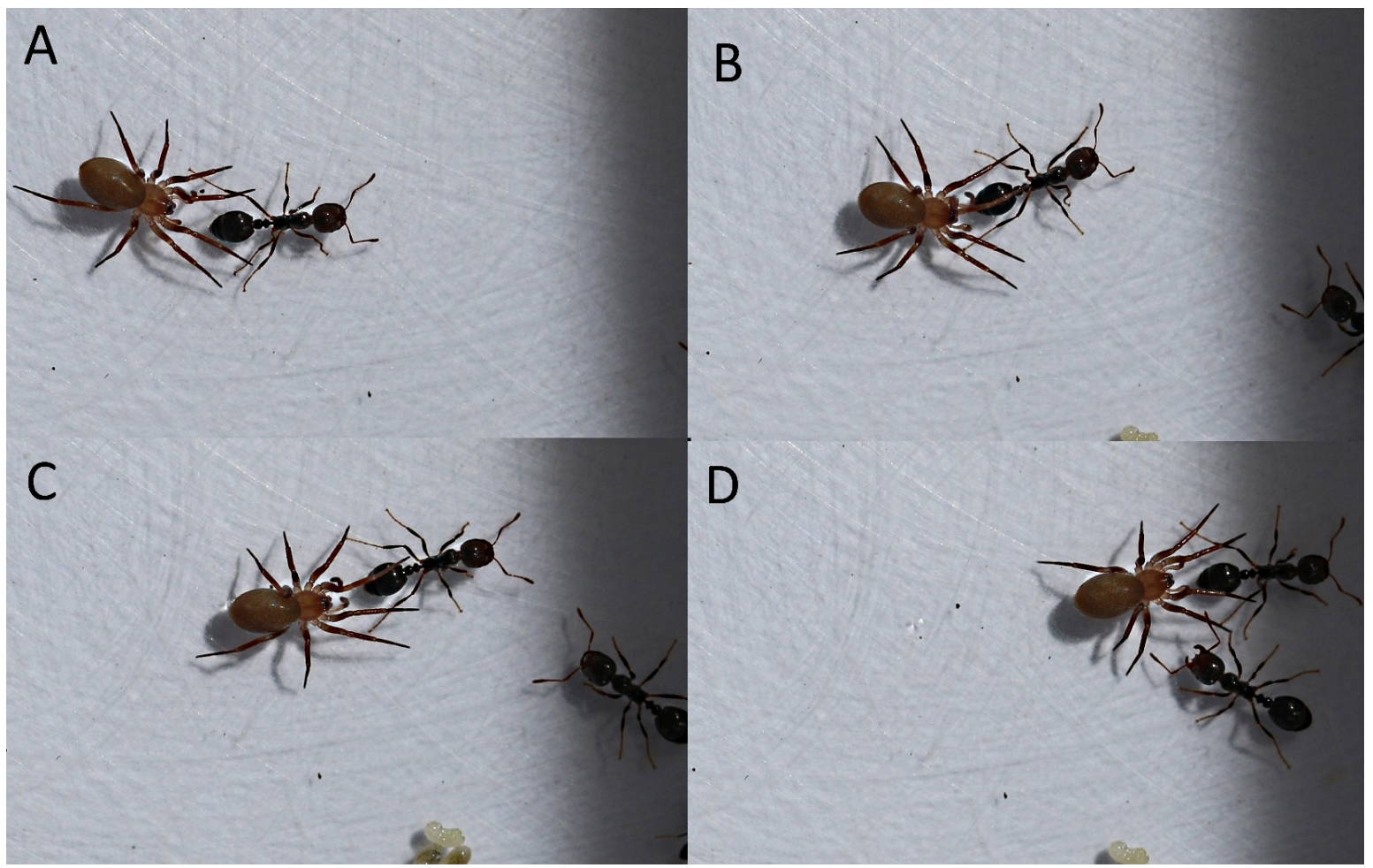

Fig 1. Attacobius lavape female closely following and touching the Solenopsis saevissima workers in a colony maintained in laboratory. A-D: sequence of persecution behavior. 


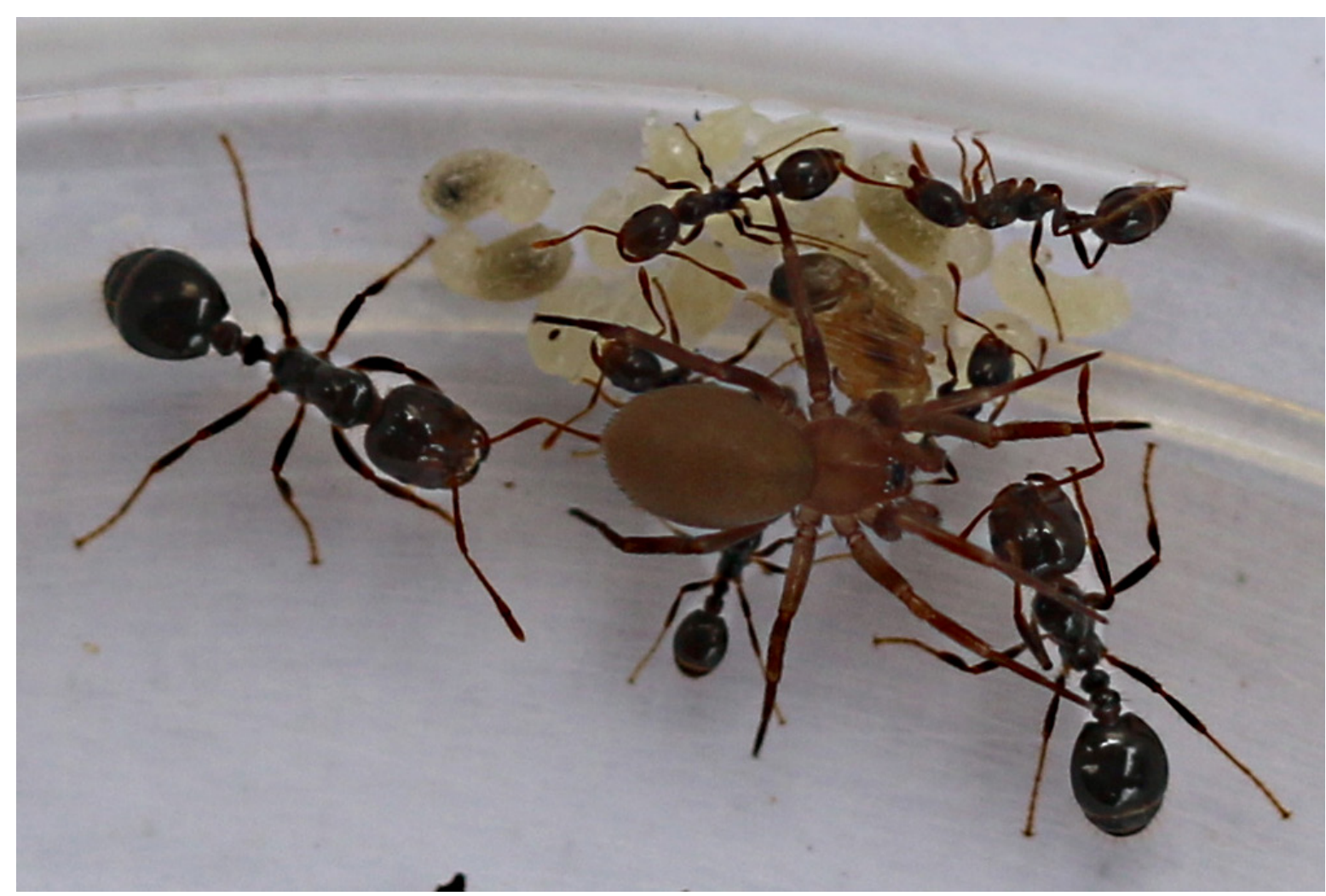

Fig 2. Attacobius lavape female on larvae and pupae, touching and being touched by the ants in a Solenopsis saevissima colony maintained in laboratory.

\section{Discussion}

The small size of the A. lavape adults (total length of $3.27 \mathrm{~mm}$ for females and $3.04 \mathrm{~mm}$ for males; Bonaldo et al., 2018 ) is a myrmecophilous trait that favors mobility within the colonies (Cushing, 2012), and its myrmecophily on $S$. saevissima can be explained by myrmecophagy, for example with A. attarum on Atta sexdens (Linnaeus, 1758) (Erthal \& Tonhasca, 2001). Considering that the mean abundance was approximately seven spiders per colony (extent 1-23) and each spider consumed five larvae and/or three pupae per day, we foresee an impact of 28 larvae and/or pupae per day in each hosting colony, besides the eggs that have not been quantified. In addition to reducing colony fitness, it is still necessary to consider the negative spider impact on the production of new generations through eggs, larvae and pupae predation on sexual ant castes. Regarding the growth rates of seven workers/day in S. invicta and Solenopsis richteri Forel, 1909 colonies up to five-month old (Markin \& Dillier, 1971; Markin et al., 1973), only one spider would be enough to inhibit the growth of an $S$. saevissima initial colony. Thus, A. lavape presents a significant potential as $S$. saevissima biological control agent in sites where it becomes a plague. Despite the integration of A. lavape with S. invicta observed in the specificity tests, the use of this spider in control programs in the United States still demands predation tests with colonies of Solenopsis geminata (Fabricius, 1804) (a native species of the country), and species of other genus and subfamilies.
In fact, some species of myrmecophilous spiders may use up to three genera and five species different as hosts (Cushing, 1997).

Together with other natural enemies (Briano et al., 2012), A. lavape preys on fire ants and helps to keep a low colony density in South America. In the southern United States, where $S$. invicta was accidentally introduced without natural enemies (Porter et al., 1997), the colony density is 16 times higher than S. saevissima density found in Morrinhos $(12.95 \pm 6.48$ colonies/ha), but the relationship of this low density to the presence of $A$. lavape needs to be further evaluated. The fact that the A. lavape occurs in $42 \%$ of the sites with $S$. saevissima and $47 \%$ of the colonies in the sites where it occurred demonstrates a "high local infestation and high regional transmission" pattern, different from the three distribution models of social parasite pointed by Thomas et al. (2005). Just as environmental disturbances may favor the population growth of $S$. invicta (LeBrun et al., 2012), the large expansion of agribusiness and the consequent reduction of native vegetation in the southern region of Goiás (Costa \& Santos, 2010) may have favored the dispersal of S. saevissima and its guest $A$. lavape. The absence of $A$. lavape towards the São Paulo State suggests endemism of the species in the Morrinhos region. However, more collections towards the north, east and west regions of the municipality are necessary to confirm this hypothesis.

The presence of very young individuals and adults of both sexes indicate that $A$. lavape reproduces inside the hosting ant colony, being a probably obligate guest (Cushing, 1997). 
Despite the risks for the inquiline spider, such as to be identified during the mating and have its eggs destroyed by the ants (Edmunds, 1978), the use of the colony interior as a reproduction site has already been observed for the Eilica myrmecophila (Simon, 1903) (in synonymy Eilica puno) (Gnaphosidae) spider and Camponotus inca Emery, 1903 ant (Noonan, 1982). Attacobius lavape behavior of closely following and touching the workers has also been observed with $A$. attarum on A. sexdens (Erthal \& Tonhasca, 2001). This behavior suggests that the renewal or the restoration of the cuticle chemical profile by the spider is not regulated via biosynthesis, but by continuous exogenous transfer, indicating the use of chemical camouflage to remain in the hosting colony (Dettner \& Liepert, 1994). When the Varroa destructor Anderson and Trueman, 2000 mite was experimentally introduced in one colony of a different host bee species (Apis cerana Fabricius, 1793), it acquired a chemical profile similar to the new hosting species demonstrating chemical camouflage of the parasite mite (Kather et al., 2015). In fact, no case of chemical mimicry by biosynthesis has been attributed to the myrmecophilous spiders, and the integration with the ant colonies occurs by the contact with the nest material, contact with the workers or by the predation of larvae and pupae (Cushing, 2012), yet some cuticular hydrocarbon studies are necessary to confirm this hypothesis.

\section{Supplementary Material}

http://periodicos.uefs.br/index.php/sociobiology/rt/ suppFiles/4431/0

\section{Acknowledgements}

Two anonymous reviewers of the manuscript provided several insightful suggestions. This study was financed in part by the Coordenação de Aperfeiçoamento de Pessoal de Nível Superior - Brazil (CAPES) - Finance Code 001 (Convênio n ${ }^{\circ}$ 17164/2015 CAPES/PROAP and CAPES/FAPEG $n^{\circ}$ 1656/2016). We also thank the PrP/UEG and Programa de Concessão de Bolsa de Incentivo ao Pesquisador (PROBIPUEG) for scholarship granted.

\section{References}

Ayres, M., Ayres, M. Jr, Ayres, D.L. \& Santos, A.A.S. (2007). BioEstat: aplicações estatísticas nas áreas das ciências biomédicas. 5 ed. Belém: Sociedade Civil Mamirauá.

Bonaldo, A.B. (2000). Taxonomia da subfamília Corinninae (Araneae, Corinnidae) nas regiões Neotropical e Neártica. Iheringia, Série Zoologia, 89: 3-148. doi: 10.1590/S007347212000000200001

Bonaldo, A.B. \& Brescovit, A.D. (2005). On new species of the Neotropical spider genus Attacobius Mello-Leitão, 1923 (Araneae, Corinnidae, Corinninae), with a cladistic analysis of the tribe Attacobiini. Insect Systematics and Evolution, 36: 35-56, doi: 10.1163/187631205788912804
Bonaldo, A.B., Pesquero, M.A. \& Brescovit, A.D. (2018). On a new species of the spider genus Attacobius Mello-Leitão (Araneae: Corinnidae) from Brazilian Cerrado. Zootaxa, 4508: 446. doi: 10.11646/zootaxa.4508.3.10

Briano, J., Calcaterra, L. \& Varone, L. (2012). Fire ants (Solenopsis spp.) and theirnatural enemies in southern South America. Psyche, Article ID 198084, 19 p., doi: 10.11 55/2012/198084

Ceccarelli, F.S. (2013). Ant-Mimicking spiders: strategies for living with social insects. Psyche, Article ID 839181, 6 p., doi: $10.1155 / 2013 / 839181$

Costa, R.A. \& Santos, F.O. (2010). Expansão agrícola e vulnerabilidade natural do meio físico no sul goiano. Revista Geografia em Atos, 10: 23-35.

Cushing, P.E. (1997). Myrmecomorphy and myrmecophily in spiders: a review. Florida Entomologist, 80: 165-193, doi: $10.2307 / 3495552$

Cushing, P.E. (2012). Spider-ant associations: an updated review of myrmecomorphy, myrmecophily, and myrmecophagy in spiders. Psyche, Article ID 151989, 23 p. doi: $10.1155 / 2012 / 151989$

Del-Claro, K. (2010). Introdução à ecologia comportamental: um manual para o estudo do comportamento animal. Rio de Janeiro: Technical Books.

Dettner, K. \& Liepert, C. (1994).Chemical mimicry and camouflage. Annual Review of Entomology, 39: 129-154, doi: 10.1146/annurev.en.39.010194.001021

Edmunds, M. (1978). On the association between Myrmurachne spp. (Salticidae) and ants. Bulletin - British Arachnological Society, 4: 149-160.

Erthal Jr, M. \& Tonhasca Jr, A. (2001). Attacobius attarum Spiders (Corinnidae): myrmecophilous predators of immature forms of the leaf-cutting ant Atta sexdens (Formicidae). Biotropica, 33: 374-376. doi: 10.1646/0006-3606(2001) 033[0374:AASCMP]2.0.CO;2

Hamilton, W.D. (1964). The genetical evolution of social behaviour, I. Journal of Theoretical Biology, 7: 1-16. doi: 10.1016/0022-5193(64)90038-4

Hamilton, W.D. (1964). The genetical evolution of social behaviour, II. Journal of Theoretical Biology, 7: 17-52. doi: 10.10 16/0022-5193(64)90039-6

Hölldobler, B. \& Wilson, E.O. (1990). The Ants. Cambridge: Harvard University Press, 732 p.

Ichinose, K., Rinaldi, I. \& Forti, L.C. (2004). Winged leafcutting ants on nuptial flights used as transport by Attacobius spiders for dispersal. Ecological Entomology, 29: 628-631, doi: 10.1111/j.0307-6946.2004.00640.x

Kather, R., Drijfhout, F.P., Shemil,T.S. \& Martin, S.J. (2015). Evidence for passive chemical camouflage in the parasitic 
mite Varroa destructor. Journal of Chemical Ecology, 41: 178-186. doi: 10.1007/s10886-015-0548-z

Lebrun, E.G., Plowes, R.M. \& Gilbert, L.E. (2012). Imported fire ants near the edge of their range: disturbance and moisture determine prevalence and impact of an invasive social insect. Journal of Animal Ecology, 81: 884-895. doi: 10.1111/j.13652656.2012.01954.x

Markin, G.P. \& Dillier, J.H. (1971). The seasonal life cycle of the imported fire ant, Solenopsis saevissima richteri, on the gulf coast of Mississippi. Annals of the Entomological Society of America, 64: 562-565. doi: 10.1093/aesa/64.3.562

Markin, G.P., Dillier, J.H. \& Collins, H.L. (1973).Growth and development of colonies of the red imported fire ant, Solenopsis invicta. Annals of the Entomological Society of America, 66: 803-808. doi: 10.1093/aesa/66.4.803

Noonan, G.R. (1982). Notes on interactions between the spider Eilicapuno (Gnaphosidae) and the ant Camponotusinca in the Peruvian Andes. Biotropical, 14: 145-148. doi: $10.2307 / 2387745$

Pereira-Filho, J.M.B., Saturnino, R. \& Bonaldo, A. (2018). Five new species and novel descriptions of opposed sexes of four species of the spider genus Attacobius (Araneae: Corinnidae). Zootaxa, 4462: 211. doi: 10.11646/zootaxa.4462.2.3

Pesquero, M.A. \& Dias, A.M.P.M. (2004). New records of Orasemaxanthopus (Hymenoptera: Eucharitidae) and Solenopsis daguerrei (Hymenoptera: Formicidae) from Brazil. Brazilian Journal of Biology, 64: 737. doi: 10.1590/ S1519-69842004000400023
Pesquero, M.A. \& Dias, A.M.P.M. (2011). Geographical transition zone of Solenopsis fire ants (Hymenoptera: Formicidae) and Pseudacteon fly parasitoids (Diptera: Phoridae) in the State of São Paulo, Brazil. Neotropical Entomology, 40: 647-652. doi: 10.1590/S1519-566X2011000600003

Pitts, J.P., Camacho, G.P., Gotzek, D., Mchugh, J.V. \& Ross, K.G. (2018). Revision of the fire ants of the Solenopsis saevissima species-group (Hymenoptera: Formicidae). Proceedings of the Entomological Society of Washington, 120: 308-411. doi: 10.4289/0013-8797.120.2.308

Platnick, N.I. \& Baptista, R.L.C. (1995). On the spider genus Attacobius (Araneae, Dionycha). American Museum of Natural History, no. 3120, 9 p.

Porter, S.D., Williams, D.F., Patterson, R.S. \& Fowler, H.G. (1997). Intercontinental differences in the abundance of Solenopsis fire ants (Hymenoptera: Formicidae): Escape from natural enemies? Environmental Entomology, 26: 373-384.

Thomas, A.J., Schonrogge, K. \& Elmes, G.W. (2005). Specializations and host associations of social parasites of ants. In Fellowes, M.D.E., Holloway, G.J. \& Rolff, J. (Eds.) Insect Evolutionary Ecology (pp. 479-518). UK: Royal Entomological Society, CABI Publishing.

Tschinkel, W.R. (2006). The fire ants. Cambridge, Massachusetts: Belknap Press of Harvard University Press.

WSC (2019). World spider catalog. Natural History Museum Bern. http://wsc.nmbe.ch, version 18.5. (accessed: 25 jan, 2019).

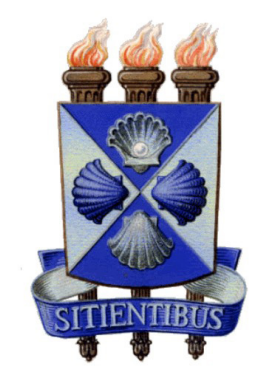

